\title{
Osteoporosis screening for patients with prolonged use of glucocorticoid in national guard hospital - Jeddah, Saudi Arabia
}

\begin{abstract}
Background: Glucocorticoid therapy is the most common secondary cause leading to osteoporosis. Bone mineral density testing is recommended for those who are going to use steroids for more than three or six months. However, many patients are on prolonged steroid therapy and have never been screened for osteoporosis.
\end{abstract}

Objective: The aim of this study was to assess if patients with prolonged use of steroids are checked for osteoporosis in National Guard Hospital, Jeddah, Saudi Arabia.

Methods: This cross-sectional study was carried out on male and female patients on $5 \mathrm{mg}$ of prednisolone for more than 6months in National Guard Hospital, Jeddah, Saudi Arabia Data were extracted from patients' files and included patients' demographics; dose and duration of prednisolone use; screening for osteoporosis and medication taken to treat or prevent osteoporosis.

Results: Files of 362 patients were included. Most patients were women (82.6\%) and had prednisolone dose $\geq 5 \mathrm{mg}$ daily for more than 6 months $(78.5 \%)$. Those diagnosed with osteoporosis constituted 21\%. Dual energy x-ray absorptiometry (DEXA) scan was done in $40.9 \%$ of patients, irrespective of the dose or duration of use of prednisolone. The majority of patients were given calcium and vitamin D (93.9\% and $84.5 \%$, respectively); while only $27.1 \%$ had bisphosphonate. Increase in age was associated with a decreased risk (patients were more likely to have DEXA scan); while patients with increased body mass index (BMI) were more likely not to have DEXA scan, compared to the underweight.

Conclusion: the rates of DEXA Scan performance were suboptimal. Treatment received by the patients on chronic steroid medications is satisfactory to a large extent. However, doctors' awareness should be raised as regards patients at high risk of developing glucocorticoid induced osteoporosis (GIOP) and the appropriate use of bisphosphonates. We recommend developing National Saudi Guidelines for management of GIOP, and it should be distributed to all health care facilities that manage those patients.
Volume 7 Issue 4 - 2019

\author{
Salwa Al-Aidarous,' Faisal Al-Husayni, ${ }^{2}$ Jehad \\ Alzahrani, ${ }^{2}$ Shahad Sarhan, ${ }^{3}$ Rawah Foudah, ${ }^{3}$ \\ Laila Alqurashi, ${ }^{3}$ Maha Alharbi ${ }^{4}$ \\ 'Department of Endocrinology, King Saud Bin Abdulaziz \\ University for Health Sciences, National Guard Hospital, Saudi \\ Arabia \\ ${ }^{2}$ Department of Medicine, National Guard Hospital, Saudi Arabia \\ ${ }^{3}$ College of Medicine, King Saud Bin Abdulaziz University for \\ Health Sciences, National Guard Hospital, Saudi Arabia \\ ${ }^{4}$ Department of Nursing, King Saud Bin Abdulaziz University for \\ Health Sciences, National Guard Hospital, Saudi Arabia
}

\section{Correspondence: Salwa Al-Aidarous, Department of endocrinology, King Saud Bin Abdulaziz University for Health Sciences, National Guard Hospital, Jeddah, Saudi Arabia, Tel} 00966505643462,Email Salirous@yahoo.com

Received: July 21, 2019 | Published: August 06, 2019

Keywords: glucocorticoids, osteoporosis, DEXA scan, calcium, vitamin D, bisphosphonates

\section{Introduction}

Osteoporosis is a disease characterized by a decrease in the density of normally mineralized bones and an increased risk of fragility fractures. ${ }^{1}$ It is a worldwide problem especially in developed countries, where it represents the most prevalent metabolic bone disease. ${ }^{2}$ Osteoporosis can affect both males and females. It has been estimated that about one-half of all postmenopausal women and onequarter of white men over 60years of age will sustain a fracture as a result of osteoporosis in their lifetime. ${ }^{3}$ In Saudi Arabia, 34\% of women and $30.7 \%$ of men aged 50-79years suffer from osteoporosis. ${ }^{4}$

Osteoporosis is usually asymptomatic and manifests as fractures of hip, vertebra, or other bones. The gold standard diagnostic method is dual energy x-ray absorptiometry (DEXA) scan, and the diagnosis is made when the bone density is equal or less than 2.5 standard deviation below that of a young adult. ${ }^{5}$ However, most individuals with osteoporosis remain undiagnosed and untreated. It has been reported that despite an expected prevalence of about $25 \%$ among women over $60 y$ ears, less than $2 \%$ of them were diagnosed as having osteoporosis by their primary care physicians, and only onethird of diagnosed patients were given the proper drug therapy. ${ }^{6}$ The problem of misdiagnosis and under-treatment is even worse in men with osteoporosis. ${ }^{7}$ Several risk factors contribute to osteoporosis, and they are classified into primary and secondary factors. Primary risk factors, such as increasing age and female gender, are the most common among all factors. Secondary risk factors are potentially modifiable and include chronic glucocorticoid use, hyperthyroidism, hyperparathyroidism, alcohol abuse, vitamin D deficiency, and immobilization. Among all secondary causes, glucocorticoid-induced osteoporosis (GIOP) is the most common secondary cause leading to osteoporosis. ${ }^{1}$ Glucocorticoids are considered the mainstay treatment of variety of diseases. However, the risk of GIOP is significantly associated with the duration and dose of glucocorticoid use. It is estimated that the overall risk of GIOP after 6months of steroid use is $50 \%$, while fracture risk after fiveyears of its use is $30 \% \cdot{ }^{8,9}$ Regarding the dose, glucocorticoids at doses as low as prednisone $3 \mathrm{mg}$ are associated with fractures. ${ }^{10}$

The mechanism of GIOP is unknown, however some theories suggest that steroids have an inhibitory effect on osteoblasts. In addition, it is suggested that steroids decrease intestinal absorption of calcium and increase its renal excretion. ${ }^{11}$ Due to the high risk of 
fracture and related disabilities caused by GIOP, multiple guidelines have been released about the screening of osteoporosis for patients on steroid treatment or planned to start glucocorticoid therapy. For example, the American College of Rheumatology recommends bone mineral density (BMD) testing for patients planned to use steroids for more than sixmonths, while Osteoporosis Society of Canada recommends BMD testing for all patients having more than $2.5 \mathrm{mg} /$ day prednisone for more than 3months. ${ }^{12}$ However, many patients are on prolonged steroid therapy and have never been screened for osteoporosis. So, the aim of this study was to assess if patients with prolonged use of steroids are checked for osteoporosis in the National Guard Hospital, Jeddah, Saudi Arabia.

\section{Methods}

\section{Ethical considerations:}

The study got an ethical approval from the Institutional Review Board of King Abdullah International Medical Research Center, Jeddah, Saudi Arabia. Confidentiality of the collected data and participant's privacy were assured, and the data were used only for research purpose. The study did not have any physical, psychological, social, legal, economic, or any other anticipated risks to participants, and it did not present a direct benefit for the study's participants.

\section{Study design}

A descriptive, cross-sectional design was adopted.

\section{Participant's eligibility criteria}

The target population of this study was male and female patients on $5 \mathrm{mg}$ of prednisolone or more daily for 6months or more in the National Guard Hospital, Jeddah, Saudi Arabia. Patients diagnosed with hyperparathyroidism, those on prednisolone less than $5 \mathrm{mg}, 5 \mathrm{mg}$ for less than 6months and patients using prednisolone for less than one month were excluded from the study.

\section{Sample size and sampling technique}

According to Ledwich and Clarke, ${ }^{13}$ the percentage of patients on corticosteroid who were checked for osteoporosis were $37 \%$. Hence, to reach our aim, we needed to recruit 352 participants to be $95 \%$ confident with $5 \%$ margin of error. We used a consecutive sampling technique to include patients' files meeting the inclusion criteria until the calculated sample size is met.

\section{Setting and dates}

The study was conducted in the National Guard Hospital, Jeddah, Saudi Arabia. Data collection was done during the period from $1^{\text {st }}$ of April, 2019 to $31^{\text {st }}$ of May, 2019.

\section{Data collection instrument}

The data were collected from patients' files, and included patients' demographics (age, gender, BMI); the dose and duration of prednisolone use; screening for osteoporosis (including vitamin D and calcium blood levels, thyroid function tests, and DEXA scan); and preventive or treatment measures for osteoporosis.

\section{Data entry and statistical analysis}

Data analysis was carried out using SPSS version 22. All numerical variables were checked for normality by Shapiro-Wilk test. Normally distributed variables were expressed as means \pm standard deviation, and differences between groups were tested by Student's unpaired $\mathrm{T}$ test. Categorical variables were summarized as frequencies and percentages, and association between variables was tested using Pearson's Chi square or Fisher-Freeman-Halton Exact Tests as appropriate. Binary logistic regression analysis was carried out to identify factors that affect screening with DEXA Scan. A p-value of $<0.05$ was considered statistically significant.

\section{Results}

The files of 362 patients were included. Figure 1 illustrates that the study sample consisted mostly of women $(82.6 \%)$; the most frequently prescribed prednisolone dose $\geq 5 \mathrm{mg}$ daily (78.5\%); and those diagnosed with osteoporosis constituted $21 \%$.

Table 1 summarizes the sociodemographic data of the studied patients. The age of the studied sample ranged from 15 to 86 years old; with a mean age $49.1 \pm 15$. Evaluation of the BMI revealed that $30.1 \%$ were obese; $24.6 \%$ were overweight; and $19.6 \%$ were extremely obese. The duration of prednisolone use was above 12 to 24 months in most cases $(72.3 \%)$. Patients were categorized into two groups according to the prednisolone dose (those administering $\geq 5 \mathrm{mg}$ daily for more than 3 months and $7 \mathrm{mg}$ or more daily for more than 1 month). There was no significant difference in the age between the two groups $(\mathrm{p}=0.294)$. Also, there was no significant association between dose and gender $(\mathrm{p}=0.385)$ or BMI $(\mathrm{p}=0.065)$. A significantly higher frequency of patients on the $>7 \mathrm{mg}$ dose administered prednisolone for either $3-6$ months $(16.7 \%)$, or $>24$ months $(48.7 \%)$; while a significantly higher frequency of patients on the $\geq 5 \mathrm{mg}$ dose have taken treatment for $>12-24$ months $(78.9 \%$ ) (Figure 2). Study of the patients diagnosed with osteoporosis showed that they had higher mean age (62.6 $5 \pm 12.4$ vs $45.5 \pm 14.3)$; while no significant association existed with gender $(\mathrm{p}=0.676)$, BMI $(\mathrm{p}=0.389)$, dose of prednisolone $(\mathrm{p}=0.289)$, or duration $(\mathrm{p}=0.227)$.

Table 2 shows the screening tests done for diagnosis of osteoporosis, as well as the received prophylaxis/treatment. The most frequently performed tests included levels of: albumin (99.2\%), alkaline phosphatase $(98.6 \%)$, vitamin D (95\%), and creatinine (93.6\%). The least performed test was calcium level (1.1\%). DEXA Scan was done in $40.9 \%$ only of patients. The prophylaxis/treatment received in the majority of cases was calcium $(93.9 \%)$ and vitamin D (84.5\%); Bisphosphonate was administered in $27.1 \%$ of cases only. There was no significant association between the dose of prednisolone and any of the screening tests (except for parathormone level that was performed more in those taking $>7 \mathrm{mg}$ ); and the prophylaxis/treatment (except for calcium that was administered more frequently in those taking $\geq 5 \mathrm{mg}$ ). As regards gender, there was no significant association with any of the tests done (except for DEXA Scan that was performed more frequently in women). A significantly higher frequency of men administered bisphosphonate. The number of patients who did not receive any treatment was $6(1.7 \%$ of total cases $)$; half of them were diagnosed with osteoporosis. Most patients had two drugs (65.2\%), $21 \%$ had three drugs, and $12.2 \%$ had only one drug; with no significant difference between the two prednisolone doses. A significantly higher percentage of women had three drugs $(23.4 \%$ vs $9.5 \%$; $=0.045)$. Figure 3 illustrates the duration of use of prednisolone and having DEXA Scan or medications. There was no significant association $(\mathrm{p}>0.05)$.

Table 3 demonstrates the screening tests and the received prophylaxis/treatment in men above 70years and women above 
65years-who are at high risk of developing osteoporosis. In all cases, levels of alkaline phosphatase, and albumin were performed. The frequency of performing screening tests was generally higher than the total sample. The most commonly used prophylaxis/treatment was vitamin $\mathrm{D}$ in men above 70years and calcium in women above 65 years. Also, bisphosphonate was administered by more women than men. All the three men had two drugs; while $7 \%$ of women had no drugs at all. Table 4 defined the characteristics of patients at risk of not having DEXA Scan, while being on long term steroid therapy. Only age and BMI had a significant effect. Increase in age was associated with a decreased risk (patients were more likely to have DEXA Scan); while patients with increased BMI were more likely to not have the investigation, compared to the underweight.

Table I Sociodemographic data of the studied patients

\begin{tabular}{|c|c|c|c|c|c|c|c|c|c|c|c|}
\hline \multirow[b]{3}{*}{ Age } & \multirow[b]{3}{*}{ Min-Max } & \multirow{2}{*}{\multicolumn{2}{|c|}{ Total $(n=362)$}} & \multicolumn{4}{|l|}{ Dose } & \multicolumn{4}{|c|}{ Osteoporosis } \\
\hline & & & & \multicolumn{2}{|c|}{$\begin{array}{l}\geq 5 \mathrm{mg} \text { daily } \\
(\mathrm{n}=284)\end{array}$} & \multicolumn{2}{|c|}{$\begin{array}{l}\text { 7mg daily } \\
(n=78)\end{array}$} & \multicolumn{2}{|c|}{ Yes $(n=76)$} & \multicolumn{2}{|c|}{ No $(n=286)$} \\
\hline & & 15 & 86 & 15 & 84 & 21 & 86 & 25 & 84 & 15 & 86 \\
\hline & Mean \pm SD & 49.1 & 15.6 & 48.7 & 16.2 & 50.5 & 13.2 & 62.6 & 12.4 & 45.5 & 14.3 \\
\hline & $P$ & & & 0.294 & & & & $<0.00$ & & & \\
\hline \multirow[t]{3}{*}{ Gender } & Male & 63 & $17.40 \%$ & 52 & $18.30 \%$ & II & $14.10 \%$ & 12 & $15.80 \%$ & 51 & $17.80 \%$ \\
\hline & Female & 299 & $82.60 \%$ & 232 & $81.70 \%$ & 67 & $85.90 \%$ & 64 & $84.20 \%$ & 235 & $82.20 \%$ \\
\hline & $P$ & & & 0.385 & & & & 0.676 & & & \\
\hline \multirow[t]{6}{*}{ BMI } & Underweight & 15 & $4.10 \%$ & 13 & $4.60 \%$ & 2 & $2.60 \%$ & 4 & $5.30 \%$ & 11 & $3.80 \%$ \\
\hline & Normal & 78 & $21.50 \%$ & 62 & $21.80 \%$ & 16 & $20.50 \%$ & 15 & $19.70 \%$ & 63 & $22.00 \%$ \\
\hline & Overweight & 89 & $24.60 \%$ & 63 & $22.20 \%$ & 26 & $33.30 \%$ & 14 & $18.40 \%$ & 75 & $26.20 \%$ \\
\hline & Obese & 109 & $30.10 \%$ & 94 & $33.10 \%$ & 15 & $19.20 \%$ & 29 & $38.20 \%$ & 80 & $28.00 \%$ \\
\hline & Extremely obese & 71 & $19.60 \%$ & 52 & $18.30 \%$ & 19 & $24.40 \%$ & 14 & $18.40 \%$ & 57 & $19.90 \%$ \\
\hline & $P$ & & & 0.065 & & & & 0.389 & & & \\
\hline \multirow[t]{3}{*}{$\begin{array}{l}\text { Dose of } \\
\text { prednisolone }\end{array}$} & $\begin{array}{l}\geq 5 \mathrm{mg} \text { daily for } \geq 6 \\
\text { months }\end{array}$ & 284 & $78.50 \%$ & & & & & 63 & $82.90 \%$ & 221 & $77.30 \%$ \\
\hline & $7 m g$ daily & 78 & $21.50 \%$ & & & & & 13 & $17.10 \%$ & 65 & $22.70 \%$ \\
\hline & $P$ & & & & & & & 0.289 & & & \\
\hline \multirow[t]{6}{*}{ Duration } & $\leq 3$ months & 13 & $3.50 \%$ & 0 & $0.00 \%$ & 13 & 16.7 & 0 & $0.00 \%$ & 14 & $4.90 \%$ \\
\hline & 3-6months & 12 & $3.30 \%$ & 0 & $0.00 \%$ & 12 & 15.4 & 2 & $2.60 \%$ & II & $3.80 \%$ \\
\hline & $>6-12$ months & 60 & $16.60 \%$ & 48 & $16.90 \%$ & 12 & 15.4 & 11 & $14.50 \%$ & 49 & $17.10 \%$ \\
\hline & $>12-24$ months & 262 & $72.30 \%$ & 224 & $78.90 \%$ & 38 & 48.7 & 61 & $80.30 \%$ & 199 & $69.60 \%$ \\
\hline & $>24$ months & 15 & $4.10 \%$ & 12 & $4.20 \%$ & 3 & 3.8 & 2 & $2.60 \%$ & 13 & $4.50 \%$ \\
\hline & $\mathrm{p}$ & & & $<0.00 I^{*}$ & & & & 0.227 & & & \\
\hline
\end{tabular}

*significant at $\mathrm{p}<0.05$. 
Table 2 Screening for osteoporosis and treatment in the studied groups

\begin{tabular}{|c|c|c|c|c|c|c|c|c|c|c|c|c|c|}
\hline & & \multirow{2}{*}{\multicolumn{2}{|c|}{ Total }} & \multirow{2}{*}{\multicolumn{2}{|c|}{$\begin{array}{l}\text { Osteoporosis } \\
\text { Yes }(n=76)\end{array}$}} & \multicolumn{4}{|l|}{ Dose } & \multicolumn{4}{|c|}{ Gender } \\
\hline & & & & & & \multicolumn{2}{|c|}{$\begin{array}{l}\geq 5 \mathrm{mg} \text { daily } \\
(\mathrm{n}=284)\end{array}$} & \multicolumn{2}{|c|}{$\begin{array}{l}\text { 7mg daily } \\
(n=78)\end{array}$} & \multicolumn{2}{|c|}{ Male $(n=63)$} & \multicolumn{2}{|c|}{$\begin{array}{l}\text { Female } \\
(n=299)\end{array}$} \\
\hline & & $\mathbf{n}$ & $\%$ & $\mathbf{n}$ & $\%$ & $\mathbf{n}$ & $\%$ & $\mathbf{n}$ & $\%$ & $\mathbf{n}$ & $\%$ & $\mathbf{n}$ & $\%$ \\
\hline \multicolumn{14}{|l|}{ Screening test } \\
\hline \multirow[t]{2}{*}{ Vitamin D level } & Done & 344 & $95.00 \%$ & 75 & $98.70 \%$ & 272 & $95.80 \%$ & 72 & $92.30 \%$ & 57 & $90.50 \%$ & 287 & $96.00 \%$ \\
\hline & $P$ & & & & & 0.239 & & & & 0.102 & & & \\
\hline \multirow[t]{2}{*}{ Calcium Level } & Done & 4 & $1.10 \%$ & 0 & $0.00 \%$ & 3 & $1.10 \%$ & 1 & $1.30 \%$ & 0 & $0.00 \%$ & 4 & $1.30 \%$ \\
\hline & $P$ & & & & & I & & & & I & & & \\
\hline \multirow[t]{2}{*}{ ALP level } & Done & 357 & $98.60 \%$ & 76 & $100.00 \%$ & 279 & $98.20 \%$ & 78 & $100.00 \%$ & 62 & $98.40 \%$ & 295 & $98.70 \%$ \\
\hline & $P$ & & & & & 0.589 & & & & 1 & & & \\
\hline \multirow[t]{2}{*}{ Phosphate level } & Done & 344 & $95.00 \%$ & 76 & $100.00 \%$ & 272 & $95.80 \%$ & 72 & $92.30 \%$ & 59 & $93.70 \%$ & 285 & $95.30 \%$ \\
\hline & $\mathrm{P}$ & & & & & 0.239 & & & & 0.531 & & & \\
\hline \multirow[t]{2}{*}{$\begin{array}{l}\text { Magnesium } \\
\text { level }\end{array}$} & Done & 200 & $55.20 \%$ & 35 & $46.10 \%$ & 152 & $53.50 \%$ & 48 & $61.50 \%$ & 33 & $52.40 \%$ & 167 & $55.90 \%$ \\
\hline & $P$ & & & & & 0.207 & & & & 0.614 & & & \\
\hline \multirow[t]{2}{*}{ Albumin Level } & Done & 359 & $99.20 \%$ & 76 & $100.00 \%$ & 281 & $98.90 \%$ & 78 & $100.00 \%$ & 62 & $98.40 \%$ & 297 & $99.30 \%$ \\
\hline & $P$ & & & & & I & & & & 0.437 & & & \\
\hline \multirow[t]{2}{*}{ Creatinine level } & Done & 339 & $93.60 \%$ & 75 & $98.70 \%$ & 266 & $93.70 \%$ & 73 & $93.60 \%$ & 59 & $93.70 \%$ & 280 & $93.60 \%$ \\
\hline & $P$ & & & & & 1 & & & & I & & & \\
\hline \multirow[t]{2}{*}{ PTH level } & Done & III & $30.70 \%$ & 25 & $32.90 \%$ & 79 & $27.80 \%$ & 32 & $41.00 \%$ & 13 & $20.60 \%$ & 98 & $32.80 \%$ \\
\hline & $P$ & & & & & $0.025^{*}$ & & & & 0.058 & & & \\
\hline \multirow[t]{2}{*}{ TSH level } & Done & 315 & $87.00 \%$ & 69 & $90.80 \%$ & 247 & $87.00 \%$ & 68 & $87.20 \%$ & 47 & $74.60 \%$ & 268 & $89.60 \%$ \\
\hline & $P$ & & & & & 0.961 & & & & $0.001 *$ & & & \\
\hline \multirow[t]{2}{*}{ DEXA Scan } & Done & 148 & $40.90 \%$ & 65 & $85.50 \%$ & 109 & $38.40 \%$ & 39 & $50.00 \%$ & 17 & $27.00 \%$ & $|3|$ & $43.80 \%$ \\
\hline & $\mathrm{P}$ & & & & & 0.064 & & & & $0.014 *$ & & & \\
\hline \multicolumn{14}{|c|}{ Prophylaxis/treatment } \\
\hline \multirow[t]{2}{*}{ Calcium } & Yes & 340 & $93.90 \%$ & 69 & $90.80 \%$ & 272 & $95.80 \%$ & 68 & $87.20 \%$ & 57 & $90.50 \%$ & 283 & $94.60 \%$ \\
\hline & $P$ & & & & & $0.012 *$ & & & & 0.242 & & & \\
\hline \multirow[t]{2}{*}{ Vitamin D } & Yes & 306 & $84.50 \%$ & 60 & $78.90 \%$ & 242 & $85.20 \%$ & 64 & $82.10 \%$ & 55 & $87.30 \%$ & 251 & $83.90 \%$ \\
\hline & $P$ & & & & & 0.494 & & & & 0.503 & & & \\
\hline Bisphosphonate & Yes & 98 & $27.10 \%$ & 47 & $61.80 \%$ & 74 & $26.10 \%$ & 24 & $30.80 \%$ & 55 & $87.30 \%$ & 209 & $69.90 \%$ \\
\hline & $P$ & & & & & 0.407 & & & & $0.005^{*}$ & & & \\
\hline $\begin{array}{l}\text { Number of } \\
\text { drugs }\end{array}$ & None & 6 & $1.70 \%$ & 3 & $3.90 \%$ & 4 & $1.40 \%$ & 2 & $2.60 \%$ & 2 & $3.20 \%$ & 4 & $1.30 \%$ \\
\hline & One & 44 & $12.20 \%$ & 5 & $6.60 \%$ & 29 & $10.20 \%$ & 15 & $19.20 \%$ & 8 & $12.70 \%$ & 36 & $12.00 \%$ \\
\hline & Two & 236 & $65.20 \%$ & 33 & $43.40 \%$ & 194 & $68.30 \%$ & 42 & $53.80 \%$ & 47 & $74.60 \%$ & 189 & $63.20 \%$ \\
\hline & Three & 76 & $21.00 \%$ & 35 & $46.10 \%$ & 57 & $20.10 \%$ & 19 & $24.40 \%$ & 6 & $9.50 \%$ & 70 & $23.40 \%$ \\
\hline & $P$ & & & & & 0.053 & & & & $0.045^{*}$ & & & \\
\hline
\end{tabular}

*significant at $\mathrm{p}<0.05$. 
Table 3 Screening for osteoporosis and treatment in the high risk groups

\begin{tabular}{|c|c|c|c|c|c|}
\hline & & \multicolumn{4}{|c|}{ Gender } \\
\hline & & \multicolumn{2}{|c|}{ Male $>70$ years } & \multicolumn{2}{|c|}{ Female $>65$ years } \\
\hline & & $\mathbf{n}$ & $\%$ & $\mathbf{n}$ & $\%$ \\
\hline \multicolumn{6}{|l|}{ Screening tests } \\
\hline Vitamin D level & Done & 3 & $100.00 \%$ & 41 & $95.30 \%$ \\
\hline Calcium Level & Done & 0 & $0.00 \%$ & 0 & $0.00 \%$ \\
\hline ALP level & Done & 3 & $100.00 \%$ & 43 & $100.00 \%$ \\
\hline Phosphate level & Done & 3 & $100.00 \%$ & 40 & $93.00 \%$ \\
\hline Magnesium level & Done & 0 & $0.00 \%$ & 25 & $58.10 \%$ \\
\hline Albumin Level & Done & 3 & $100.00 \%$ & 43 & $100.00 \%$ \\
\hline Creatinine level & Done & 3 & $100.00 \%$ & 40 & $93.00 \%$ \\
\hline PTH level & Done & 0 & $0.00 \%$ & 19 & $44.20 \%$ \\
\hline TSH level & Done & 0 & $0.00 \%$ & 39 & $90.70 \%$ \\
\hline DEXA Scan & Done & 2 & $66.70 \%$ & 32 & $74.40 \%$ \\
\hline \multicolumn{6}{|c|}{ Prophylaxis/treatment } \\
\hline Calcium & Yes & 2 & $66.70 \%$ & 38 & $88.40 \%$ \\
\hline Vitamin D & Yes & 3 & $100.00 \%$ & 30 & $69.80 \%$ \\
\hline Bisphosphonate & Yes & I & $33.30 \%$ & 17 & $39.50 \%$ \\
\hline \multirow[t]{4}{*}{$\begin{array}{l}\text { Number of } \\
\text { drugs }\end{array}$} & None & 0 & $0.00 \%$ & 3 & $7.00 \%$ \\
\hline & One & 0 & $0.00 \%$ & 8 & $18.60 \%$ \\
\hline & Two & 3 & $100.00 \%$ & 19 & $44.20 \%$ \\
\hline & Three & 0 & $0.00 \%$ & 13 & $30.20 \%$ \\
\hline
\end{tabular}

Table 4 Binomial logistic regression model to define characteristics of patients at risk of not having DEXA scan

\begin{tabular}{|c|c|c|c|c|}
\hline & \multirow[t]{2}{*}{$\mathbf{p}$} & \multirow[t]{2}{*}{$\begin{array}{l}\text { Adjusted } \\
\text { odds ratio }\end{array}$} & \multicolumn{2}{|c|}{$\begin{array}{l}95 \% \text { C.I. for odds } \\
\text { ratio }\end{array}$} \\
\hline & & & Lower & Upper \\
\hline Age & $<0.00 I^{*}$ & 0.957 & 0.942 & 0.972 \\
\hline Gender (Female) & 0.08 & 0.564 & 0.298 & $1.07 \mid$ \\
\hline BMI & $<0.00 I^{*}$ & & & \\
\hline Normal & $<0.00 I^{*}$ & 18.11 & 5.003 & 65.555 \\
\hline Overweight & $<0.001 *$ & 22.615 & 5.991 & 85.365 \\
\hline Obese & $<0.00 I^{*}$ & 20.295 & 5.442 & 75.681 \\
\hline Extremely obese & $<0.00 I^{*}$ & 17.744 & 4.51 & 69.818 \\
\hline Dose (7mg) & 0.052 & 0.542 & 0.292 & 1.005 \\
\hline Duration & 0.109 & & & \\
\hline 3-6months & 0.078 & 4.247 & 0.851 & 21.201 \\
\hline$>6-12$ months & 0.223 & 2.018 & 0.653 & 6.24 \\
\hline$>12-24$ months & 0.853 & 1.102 & 0.394 & 3.08 \\
\hline$>24$ months & 0.293 & 2.29 & 0.488 & 10.74 \\
\hline
\end{tabular}

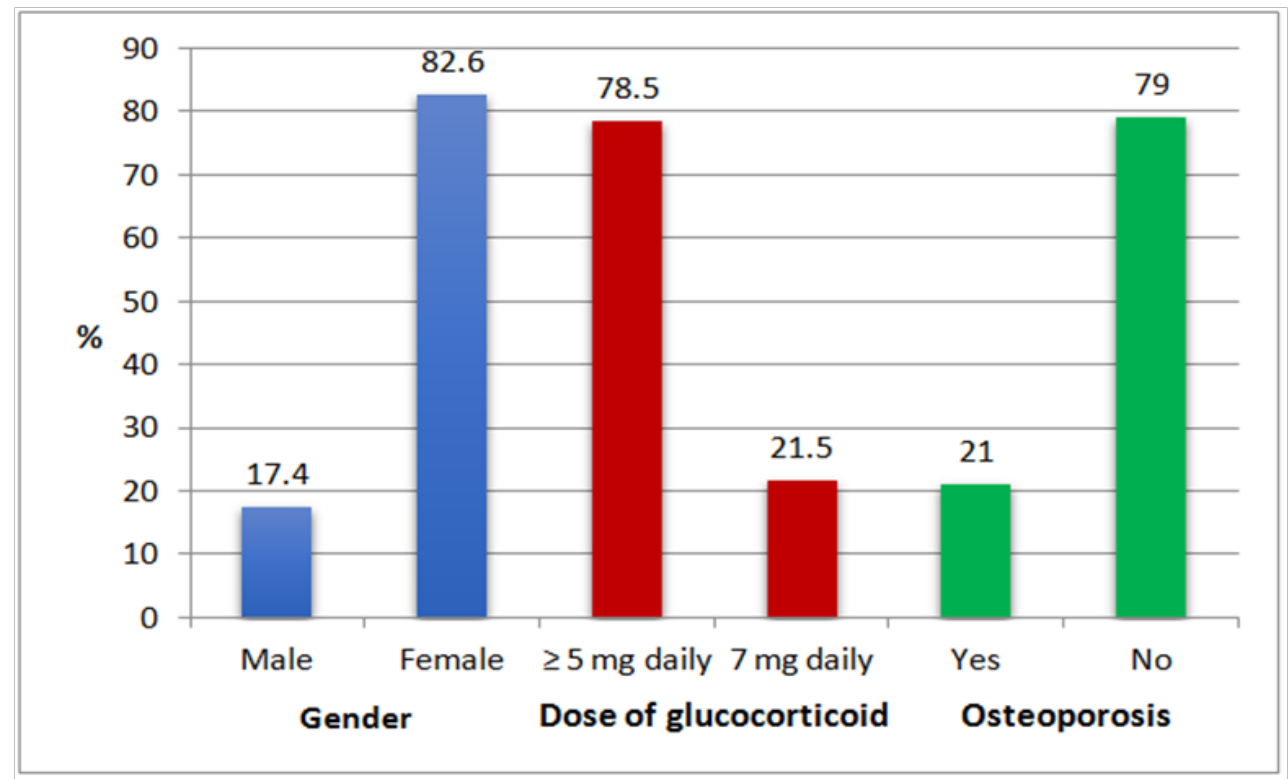

Figure I Gender, dose of prednisolone, and prevalence of osteoporosis in the studied patients.

Citation: Al-Aidarous S,Al-Husayni F,Alzahrani J, et al. Osteoporosis screening for patients with prolonged use of glucocorticoid in national guard hospital Jeddah, Saudi Arabia. Endocrinol Metab Int J. 2019;7(4):I I 3-I20. DOI: I0.15406/emij.2019.07.00254 


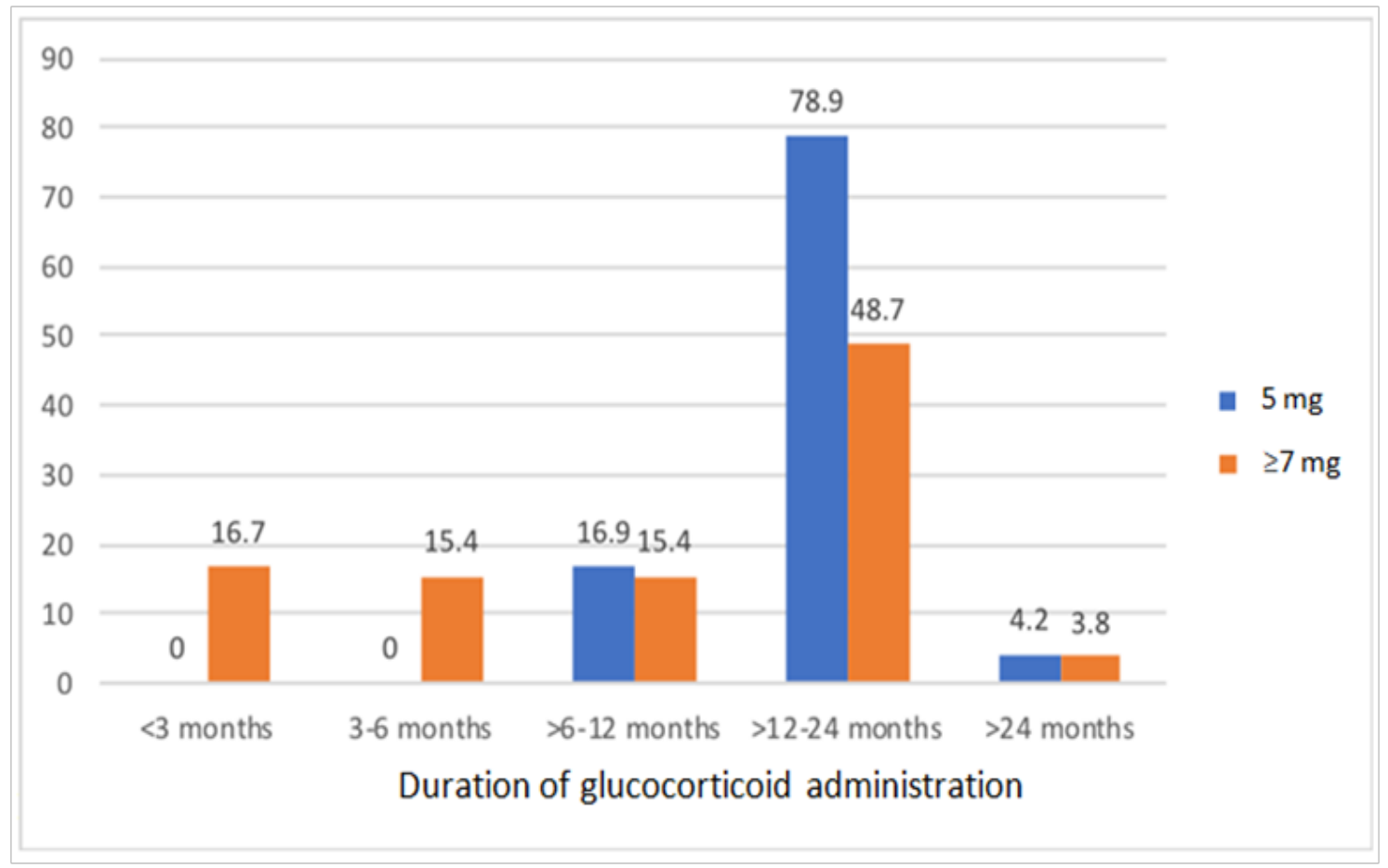

Figure 2 Dose and duration of prednisolone treatment in the studied patients.

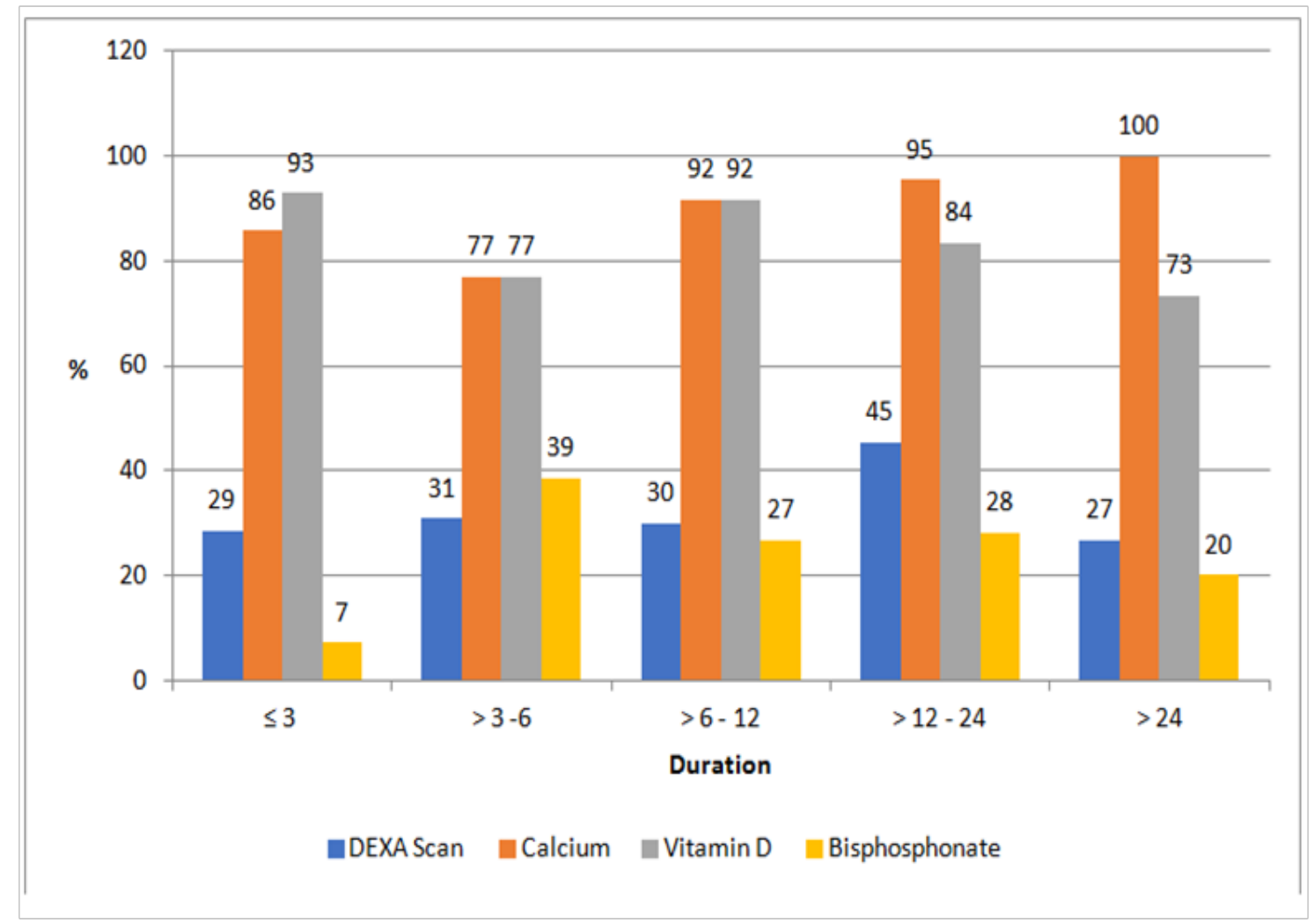

Figure 3 The duration of prednisolone use, DEXA scan, and medications. 


\section{Discussion}

In Saudi Arabia, osteoporosis affects about one third of women and men aged 50-79years. ${ }^{4}$ Chronic glucocorticoid administration ranks as the first secondary cause of osteoporosis at any age. ${ }^{1,14}$ Screening for osteoporosis is of paramount importance in patients taking glucocorticoids for long durations; and many guidelines have been developed to define methods and plans for screening. ${ }^{15}$ There is a paucity of studies in Saudi Arabia that address this important topic; only one study was carried out in King Fahd Hospital, AlKhobar. ${ }^{16}$ Therefore, the present study aimed to assess if patients with prolonged use of steroids are checked for osteoporosis in National Guard Hospital, Jeddah.

Bone densitometry is recommended in patients on long term use of steroids and T-score of -1.5 or lower indicates the need for intervention with a bone-sparing agent, for example bisphosphonates. ${ }^{17,18}$ The most frequently performed tests in this study included levels of albumin (99.2\%), alkaline phosphatase (98.6\%), vitamin D (95\%), and creatinine $(93.6 \%)$. The least performed test was calcium level (1.1\%). DEXA Scan was done in $40.9 \%$ of patients; independent of the dose or duration of steroids or the patients' gender. These percentages are higher than those reported in previous studies. ${ }^{16,19} \mathrm{~A}$ similar rate of DEXA scanning (43.4\%) was reported by Erb et al. ${ }^{20}$ In high risk cases, rates of DEXA scan were still suboptimal as the Saudi Osteoporosis Society recommended that all Saudi women above the age of 60years must undergo a BMD assessment using DEXA. ${ }^{21}$

Good nutrition, an adequate dietary intake of calcium and vitamin D, appropriate physical activity, avoidance of tobacco and alcohol should be considered for subjects receiving steroids for 3 months or more. ${ }^{17,18}$ The Effective, first-line management therapies for the prevention and treatment of glucocorticoid-induced osteoporosis include calcium and vitamin D..$^{22,23}$ The American College of Rheumatology (ACR) stated in its guideline that supplementation with calcium and vitamin $\mathrm{D}$, or an activated form of vitamin $\mathrm{D}$, should be offered to all patients receiving glucocorticoids, to restore normal calcium balance. This combination has been shown to maintain bone mass in patients receiving long-term low-to-medium-dose glucocorticoid therapy who have normal levels of gonadal hormones. ${ }^{24}$ The majority of patients in this study followed this standard as calcium and vitamin D were administered in $93.9 \%$ and $84.5 \%$ of cases, respectively. Moreover, ACR recommended also treatment with bisphosphonate to prevent bone loss in all men and postmenopausal women in whom long-term glucocorticoid treatment at $\geq 5 \mathrm{mg} /$ day is being initiated. Bisphosphonate was administered in only $27.1 \%$ of total cases in our study. A study by Sadat-Ali et al. ${ }^{16}$ in al-Khobar stated that none of their patients received bisphosphonate at all. However, similar studies were conducted and reported higher rates of bisphosphonates (35.3\%-40\%) use than ours. ${ }^{25,26}$ The number of patients who did not receive any treatment in this study was $6(1.7 \%$ of total cases) which was less than the percentage of $14 \%$ reported by Erb et al. ${ }^{20}$ However, three of them were diagnosed with osteoporosis, which raises concern about the neglect of prophylaxis then treatment in these cases.

Overall, the adherence to well-recognized recommendations for prophylaxis/treatment of GIOP in the present study was satisfactory to a large extent, as the percentage of patients who received at least one medication exceeded $80 \%$ (which is the percentage adopted by most audits). Much lower rates were reported by other older studies and audits. In the UK, Peat and colleagues reported that only $6 \%$ of their patients were receiving any osteoporosis medication. ${ }^{27}$ In another survey from the UK, $14 \%$ of patients had received treatment for the prevention of osteoporosis. ${ }^{28}$ In a study in the US, $29 \%$ of patients received some medication for osteoporosis. ${ }^{29}$ These much higher adherence rates in our study could be explained by the nature and location of this study which was conducted in one center, while many of the other studies were multi-center. Another factor also - that was unfortunately not investigated in this study - was the specialties of the treating doctors; as it was suggested that some subspecialties show more adherence than the others. ${ }^{30}$ There was no trend in rates of treatment with prescription medications for osteoporosis across glucocorticoid dosage-duration categories; an observation shared by Solomon et al. ${ }^{30}$ However, in the current study there seemed to be a neglect of the importance of bisphosphonates, particularly in at risk patients. Also, $7 \%$ of women above 65 years had no drugs at all.

We then attempted to define the characteristics of patients at risk of not having DEXA scan, while being on long term steroid therapy. Increase in age was associated with a decreased risk (patients were more likely to have DEXA scan); while patients with increased BMI were more likely to not have DEXA scan, compared to the underweight. However, Solomon et al. ${ }^{30}$ reported that men and premenopausal women were significantly more likely to not undergo bone densitometry and not receive prescription osteoporosis treatment.

\section{Conclusion}

The rates of DEXA Scan performance were suboptimal. Treatment received by the patients on chronic steroid medications is satisfactory to a large extent. However, doctors' awareness should be raised as regards patients at high risk of developing GIOP and the appropriate use of bisphosphonates. Many guidelines are available to help doctors monitor patients at risk of GIOP and prescribe prophylaxis/treatment medications. We recommend developing National Saudi Guidelines for management of GIOP that should be distributed to all health care facilities that manage those patients. Further audits should be carried out at health care facilities to record and ensure adherence to the guidelines.

\section{Acknowledgements}

We would like to thank Sawsan Khatrawi and Eiman Saleh for their support and contribution in data collection.

\section{Conflicts of interest}

The authors declare that there are no conflicts of interest.

\section{Funding}

This study received no specific funding.

\section{References}

1. Glaser DL, Kaplan FS. Osteoporosis: Definition and Clinical Presentation. Spine. 1997;22(24):12S-16S.

2. Wasnich RD. Vertebral fracture epidemiology. Bone. 1996;18(3 Suppl):179S-183S.

3. Nelson HD, Helfand M, Woolf SH, et al. Screening for postmenopausal osteoporosis: a review of the evidence for the US. Preventive Services Task Force. Ann Intern Med. 2002;137(6):529-541.

4. Sadat-Ali M, Al-Habdan IM, Al-Turki HA, et al. An epidemiological analysis of the incidence of osteoporosis and osteoporosis-related fractures among the Saudi Arabian population. Annals of Saudi medicine. 2012;32(6):637-641. 
5. Ralston SH, Fraser J. Diagnosis and management of osteoporosis. Practitioner. 2015;259(1788):15-19.

6. Gehlbach SH, Fournier M, Bigelow C. Recognition of osteoporosis by primary care physicians. Am J Public Health. 2002;92(2):271-273.

7. Kiebzak GM, Beinart GA, Perser K, et al. Undertreatment of osteoporosis in men with hip fracture. Arch Intern Med. 2002;162(19):2217-2222.

8. Adinoff AD, Hollister JR. Steroid-induced fractures and bone loss in patients with asthma. N Engl J Med. 1983;309:265-268.

9. Reid IR. Glucocorticoid induced osteoporosis, mechanisms and management. Eur J Endocrinol. 1997;137:209-17.

10. Steinbuch M, Youket TE, Cohen S. Oral glucocorticoid use is associated with an increased risk of fracture. Osteoporos Int. 2004;15(4):323-328.

11. Romas E. Corticosteroid-induced osteoporosis and fractures. Australian Prescriber. 2008;31(2):45-49.

12. Brown J, Josse R. Clinical practice guidelines for the diagnosis and management of osteoporosis in Canada. Scientific Advisory Council of the Osteoporosis Society of Canada. 2002;CMAJ167:1-34.

13. Ledwich LJ, Clarke K. Screening and treatment of glucocorticoid-induced osteoporosis in rheumatoid arthritis patients in an urban multispecialty practice. J Clin Rheumatol. 2009;15(2):61-64.

14. Alesci S, De Martino MU, Ilias I, et al. Glucocorticoid-induced osteoporosis: from basic mechanisms to clinical aspects. Neuroimmunomodulation. 2005;12(1):1-19.

15. Josse R, Canada SACotOSo. Clinical practice guidelines for the diagnosis and management of osteoporosis in Canada. CMAJ: Canadian Medical Association journal. 2002;167(10):S1-S34.

16. Sadat-Ali M, AlElq AH, Alshafei BA, et al. Osteoporosis prophylaxis in patients receiving chronic glucocorticoid therapy. Annals of Saudi Medicine. 2009;29(3):215-218.

17. Compston J, Barlow D, Browm P, et al. Glucocorticoid-induced osteoporosis: guidelines for prevention and treatment. Royal College of Physicians of London, Bone and Tooth Society, and National Osteoporosis Society Royal College of Physicians, London. 2002.

18. Compston J. US and UK guidelines for glucocorticoid-induced osteoporosis: similarities and differences. Current rheumatology reports. 2004;6(1):66-69.

19. Chanchal G, Singh VA. Glucocorticoid $\square$ induced osteoporosis: unawareness or negligence in India? International Journal of Rheumatic Diseases. 2009;12(3):230-233.
20. Erb N, Duncan RC, Raza K, et al. A regional audit of the prevention and treatment of corticosteroid-induced osteoporosis in patients with rheumatic diseases in the West Midlands. Rheumatology (Oxford, England). 2002;41(9):1021-1024

21. Al-Saleh Y, Sulimani R, Sabico S, et al. Guidelines for osteoporosis in Saudi Arabia: recommendations from the Saudi Osteoporosis Society. Annals of Saudi medicine. 2015;35(1):1.

22. Reginster JY. Treatment of postmenopausal osteoporosis. Bmj. 2005;330(7496):859-860.

23. Devogelaer JP, Goemaere S, Boonen S, et al. Evidence-based guidelines for the prevention and treatment of glucocorticoid-induced osteoporosis: a consensus document of the Belgian Bone Club. Osteoporosis international : a journal established as result of cooperation between the European Foundation for Osteoporosis and the National Osteoporosis Foundation of the USA. 2006;17(1):8-19.

24. American College ofRheumatologyAdHoc Committee Recommendations for the prevention and treatment of glucocorticoid-induced osteoporosis: 2001 update. American College of Rheumatology Ad Hoc Committee on Glucocorticoid-Induced Osteoporosis. Report No.: 0004-3591 (Print), 0004-3591 Contract No: 7. 2001

25. Hart SR, Green B. Osteoporosis prophylaxis during corticosteroid treatment: failure to prescribe. Postgraduate medical journal. 2002;78(918):242-243.

26. Lozsadi DA, Peters G, Sadik HY, et al. Prevention of osteoporosis in glucocorticoid-treated neurology patients. Clinical neurology and neurosurgery. 2006;108(2):157-162.

27. Peat ID, Healy S, Reid DM, et al. Steroid induced osteoporosis: an opportunity for prevention? Annals of the rheumatic diseases. 1995;54(1):66-68.

28. Walsh LJ, Wong CA, Pringle M, et al. Use of oral corticosteroids in the community and the prevention of secondary osteoporosis: a cross sectional study. Bmj. 1996;313(7053):344-346.

29. Osiri M, Saag KG, Ford AM, et al. Practice pattern variation among internal medicine specialists in the prevention of glucocorticoid-induced osteoporosis. Journal of clinical rheumatology: practical reports on rheumatic \& musculoskeletal diseases. 2000;6(3):117-122.

30. Solomon DH, Katz JN, Jacobs JP, et al. Management of glucocorticoidinduced osteoporosis in patients with rheumatoid arthritis: Rates and predictors of care in an academic rheumatology practice. Arthritis \& Rheumatism. 2002;46(12):3136-3142. 